Epidemiology

\title{
What are the challenges of epidemiological research during the COVID-19 pandemic?
}

\author{
Eduardo L Caputo $^{1,3}$ (1) , Natan Feter ${ }^{1,2,3}$ (1) , Airton J Rombaldi ${ }^{1,3}$ (ID), Marcelo C da Silva ${ }^{1,3}$ (D) , Felipe F Reichert ${ }^{1,3}$ (1) \\ ${ }^{1}$ Universidade Federal de Pelotas, Programa de Pós-graduação em Educação Física, Pelotas, RS, Brasil; ${ }^{2}$ Centre on Research \\ in Exercise, Physical Activity and Health, School of Human Movement and Nutrition Sciences, The University of Queensland, \\ Australia, ${ }^{3}$ Universidade Federal de Pelotas, Grupo de Estudos em Epidemiologia da Atividade Física, Pelotas, RS, Brasil.
}

Associate Editor: Angelina Zanesco. UNESP/Rio Claro, SP, Brasil.

\begin{abstract}
The COVID-19 pandemichad an impact in several areas, and in scientific research was not different. Researchers are working from theirhomes sinceresearch facilities and universities wereclosed, and face-to-faceinteraction wherelimited to stop the virus spread. This brought a lot of changes in observational studies, especially in epidemiology research. Since most studies are being conducted through internet-based assessments, researchers are facing different challenges regarding data collection and participants recruitment, for example. In this paper, we share some of the challenges faced in a populationbased study conducted in Southern Brazil, as well as possible alternatives to help researchers to overcome these issues.
\end{abstract}

Keywords: Covid-19; methods; research; epidemiology.

\section{Introduction}

In January 2020 the World Health Organization (WHO) declared the coronavirus disease (COVID-19) as a public health emergency of international concern ${ }^{1}$. Public health strategies aiming to stop the virus spread, such as social distancing and homestay, were established by many governments worldwide ${ }^{2}$ such as the closure of schools and office buildings ${ }^{3}$.

This public health strategy may disrupt health and economic conditions at individual and populational level $\mathrm{l}^{4,5}$. Additionally, scientific research has been also affected by the COVID-19 pandemic, since many researchers are working at home and face-to-face interaction were limited in academic facilities. An increase in observational studies, along with a decrease in experimental studies is expected, as a natural consequence of social restrictions. However, researches on aspects related to the pandemic (e.g. mental health, physical activity) are being conducted through remote, internet-based assessments.

We are conducting a populational-based survey to address the impact of the COVID-19 pandemic on physical and mental health, in Rio Grande do Sul state ${ }^{6}$, southern Brazil. As many other studies underway, this survey is using internet-based approaches to collect data. Here we would like to share some of the challenges we have faced and suggest possible alternatives to overcome them. We thus hope that this document be useful for future researchers collecting data during pandemic times.

Firstly, as face-to-face interaction are not recommended, and sometimes even prohibited by some research institutions, participant recruitment is being conducted by social media advertisements (e.g. Facebook, Instagram) and message sharing applications (e.g. WhatsApp) ${ }^{7}$. In this snowball recruitment strategy, the research team sends messages and advisements to their contacts, asking them to share with their friends, family members and so on ${ }^{8}$. Even though this strategy is faster and has a lower cost, compared to face-to-face interviews, it might have other limitations, such as the increased risk of selection bias. As messages and advisements are initially shared by the research team, participants may be recruited on their internet bubble $^{9}$. One alternative approach that might help researchers to avoid selection bias on general population studies is to contact local media and specific institutions (e.g. health departments) and ask them to share the research on their website and social media. If specific populations are being studied (e.g., healthcare workers), contact with associations and other unions of the target population, as well as the use of a list of participants from previous studies may increase the likelihood of a more heterogeneous sample.

Secondly, during the recruitment and on longitudinal studies, epidemiologic studies are susceptible to refusals and losses of follow-up ${ }^{10}$. In face-to-face data collection, researchers usually deal with this issue by adopting strategies such as changing the interviewer to collect the data or contacting the participant on different days/times, etc. On an internet-based approach, researchers cannot pinpoint how many people were reached. Although some social media (e.g. Instagram) allows the publisher to see how many people were reached by the advertisement posted, other message sharing platforms (e.g. WhatsApp) do not. So, it is not possible to calculate the rate of refusals/losses. However, 
a certain percentage of losses and refusals is considered in sample size calculations. Therefore, sample size calculations should be conducted prior to the beginning of data collection, and researchers should trace a recruitment strategy that allows them to reach the sample previously defined.

Thirdly, the internet-based approach does not enable an equiprobable sampling process in terms of economic status due to internet access inequality, mainly in middle- and low-income countries. This may reduce the chances of people from lower economic groups to participate in the study. According to the World Bank ${ }^{11}$, about $50 \%$ of the world population have internet access. Nevertheless, while this percentage increases up to $85 \%$ in high-income countries, only $16 \%$ and $46 \%$ of people from low- and middle-income countries have internet access, respectively. Another alternative approach to reduce the social inequality impact in the sampling process would be telephone-based interviews. However, mobile and fixed phone subscriptions illustrate a similar scenario. There are 128 and 38 subscriptions for mobile and fixed phones per 100 inhabitants in high-income countries and 66 and 1 in low-income countries, respectively. Then, inequality in internet and mobile and the fixed phone should be acknowledged as an important limitation of studies that use such approaches in the sampling process.

Fourthly, researchers should consider a shorter version of some validated questionnaires that needed to be adapted for the new COVID-19 reality, since short questionnaires (10 minutes) might increase the response rate. Usually, internet- and phonebased approaches expect a plentiful intent from participants to respond sometimes exaggeratedly-large questionnaires. This could lead researchers to design adapted versions of validated instruments to address health-related outcomes in a large representative sample. For example, consider a study aiming to examine the effects of physical activity practiced before social distancing on COVID-19-related symptoms and hospitalizations. Most of the questionnaires address physical activities practiced in a period of no more than the last 30 days. The reason for this is the lack of precision in describing the activities practiced in the past. However, at the time this letter is being written, four months have passed since social mobility restrictions were imposed by health authorities. Then, researchers with no data collected before these restrictions would depend on the participant's ability to report their physical activities practiced such a long time ago, risking recall bias to assess this important COVID-19-related behavior.

\section{Conclusion}

Here we summarized some of the challenges faced by researchers especially in low- and middle-income countries during the COVID-19 pandemic. We truly expect that these issues do not discourage researchers to study COVID-19related outcomes such as physical activity, mental health, and access to healthcare systems. These methodological aspects might negatively impact both internal and external validity. Nevertheless, we believe that the more research, the better, especially during the pandemic, so that we can get through this difficult time faster. However, researchers must interpret their findings taking into consideration the inherent limitations of some methodological choices. Each light that can be shed on the COVID-19 pandemic can help to mitigate the morbidity and mortality caused by this disease.

\section{References}

1. WHO. Statement on the second meeting of the International Health Regulations (2005) Emergency Committee regarding the outbreak of novel coronavirus (2019-nCoV) [Internet]. [cited 2020 Jun 2];Available from: https:/www.who.int/news-room/ detail/30-01-2020-statement-on-the-second-meeting-of-theinternational-health-regulations-(2005)-emergency-committeeregarding-the-outbreak-of-novel-coronavirus-(2019-ncov)

2. Islam N, Sharp, SJ, Chowell G, Shabnam S, Kawachi I, Lacey $\mathrm{B}$, et al. Physical distancing interventions and incidence of coronavirus disease 2019: natural experiment in 149 countries. BMJ; 2020; 370:m2743. Available from: http://dx.doi.org/10.1136/ bmj.m2743

3. Wilder-Smith A, Freedman DO. Isolation, quarantine, social distancing and community containment: pivotal role for old-style public health measures in the novel coronavirus (2019-nCoV) outbreak. J Travel Med. 2020; 27(2).

4. Correia S, Luck S, Verner E. Pandemics Depress the Economy, Public Health Interventions Do Not: Evidence from the 1918 Flu. SSRN Electron J. 2020;

5. Chen P, Mao L, Nassis GP, Harmer P, Ainsworth BE. Coronavirus disease (COVID-19): The need to maintain regular physical activity while taking precautions. J Sport Heal Sci. 2020; 9(2):103-4. Available from: http://www.elsevier.com/wps/ find/journaldescription.cws_home/728044/description

6. Feter N, Caputo EL, Doring IR, Leite JS, Cassuriaga J, Reichert FF, et al. Longitudinal study about low back pain, mental health, and access to healthcare system during COVID-19 pandemic: protocol of an ambispective cohort Short title: PAMPA cohort: study protocol. medRxiv. 2020; Available from https:/www. medrxiv.org/content/10.1101/2020.07.22.20160309v1

7. Moraes RR, Correa MB, Queiroz AB, Daneris A, Lopes JP, Pereira-Cenc T, et al. COVID-19 challenges to dentistry in the new pandemic epicenter: Brazil. medRxiv. 2020; 06.11.20128744. Available from: https://www.medrxiv.org/conte $\mathrm{nt} / 10.1101 / 2020.06 .11 .20128744 \mathrm{v} 1$

8. Kahan D, Al-Tamimi A. Strategies for recruiting middle Eastern-American young adults for physical activity research: A case of snowballs and Salaam. J Immigr Minor Heal. 2009; 11(5):380-90.

9. Pariser E. Editor. The filter bubble: What the internet is hiding from you. Ed. Penguin, UK, 2011.

10. Hallal PC, Bertoldi AD, Domingues MR, da Silveira MF, Demarco FF, da Silva ICM, et al. Cohort profile: The 2015 Pelotas (Brazil) birth cohort study. Int. J. Epidemiol. 2018; 47(4): 1048H.

11. Bank TW. World Development Indicators. World Dev. Indic. 2020. Available from: https://datatopics.worldbank.org/ world-development-indicators/ 


\section{Acknowledgments}

This work was supported in part by the Coordenação de Aperfeiçoamento de Pessoal de Nível Superior - Brasil (CAPES) - Finance Code 001

\section{Corresponding author}

Eduardo L Caputo. Federal University of Pelotas. Luis de Camões, 625, Três Vendas, 96055-630, Pelotas/RS, Brazil. Telephone: +55 (53) 32732752.

Email: caputoeduardo@yahoo.com.br
Manuscript received on October 26, 2020

Manuscript accepted on November 12, 2020

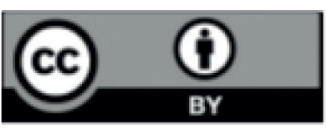

Motriz. The Journal of Physical Education. UNESP. Rio Claro, SP, Brazil - eISSN: 1980-6574 - under a license Creative Commons - Version 4.0 